\title{
An Industrial Dental-Erosion by Chromic Acid: A Case Report
}

\author{
C. Türksel Dülgergila, DDS, PhD \\ Ebru Olgun Erdemirb, DDS, PhD \\ Ertuḡrul Ercanc, DDS, PhD \\ Ali Erdemird, DDS, PhD
}

\begin{abstract}
A case of uncommon occupational dental erosion was reported in an individual who had worked in the war industry for twenty years. This occupation involved daily, at least 8 hours, inhalation of chromic acid being used for cleaning of barrel of cannons. The erosion manifested as dental sensitivity with excessive cervical erosion even with pulpal exposure in certain teeth. Moreover, due to the adverse effect of the chemical against to gingival and/or periodontal tissues, the lesions were extremely harmful with respect to the exposed root-cementum. After proper periodontal therapy, cervical lesions were treated conservatively with a compomer based restorative material without cavity preparation. Although today it is not common due to the well-controlled working conditions, occupational combined dental and medical problems via airborne fumes and/or elements can be seen at workers in chemical factories. A cumulative biohazardous effect is generally seen as not only medical but also dental disorders. (Eur $\mathrm{J}$ Dent 2007;2:119-1221
\end{abstract}

Key Words: Erosion; Chromic acid; Compomer restorative material; Cervical lesion.

\section{INTRODUCTION}

Dental erosion is defined as the loss of tooth substance by a chemical process that does not involve bacteria. It is an irreversible lesion leading to altered appearance and function and eventually to tooth loss. It can involve any tooth surface, but it

$\square$ a Associate Professor, University of Kirikkale, Dental School, Department of Operative Dentistry, Kirikkale, TURKEY.

b Assistant Professor, University of Kirikkale, Dental School, Department of Periodontics, Kirikkale, TURKEY.

c Assistant Professor. University of Kirikkale, Dental School, Department of Operative Dentistry, Kirikkale, TURKEY.

d Associate Professor. University of Kirikkale, Dental School, Department of Endodontics, Kirikkale, TURKEY.

$\square$ Corresponding Author: Dr. Ertuḡrul ERCAN University of Kırıkkale, Dental Faculty,

Department of Operative Dentistry, Mimar Sinan Caddesi, Mediko Sosyal Binası 25, 71100 Kırıkkale, Turkey. Phone: +903182243618 Fax: +903182246907 E-mail: ertugrulercanahotmail.com

is seen the most after on the facial, occlusal, and lingual surfaces. It is important to distinguish this from physical abrasion and attrition as these are sometimes confused although they can occur together.

The etiology of dental erosion can either be intrinsic or extrinsic: the former is hydrochloric acid from the stomach; the latter originates from the acidic foodstuffs, beverages, and snacks and exposure to acidic contaminants in the workplace, particularly in certain occupations. ${ }^{1-3}$ Of the specific occupations, workers in the battery factory and in the lead sealing industry have routinely been reported for the risk of dental erosion due to industrial acids exposed to the atmosphere. ${ }^{4,5}$ Generally, those involved in the chemical industry workers often complain of sensitivity and harmful wear in their teeth. Although the pattern of damage depends on the exposure time and intensity, the reviewed literature data showed that specific corrosion cases do rarely occur, especially con- 
cerning industrial harmful agents. ${ }^{6}$ Also, current industrial safety standards have lessened the occurrence of erosion associated with environmental hazards in the work area.

The previous cases of dental erosion in industry workers have been documented from hydrochloric, picric, formic, sulphuric and other acids ${ }^{3,7,8}$ but in literature there is not any case report resulting from chromic acid. Chromic acid $\mathrm{CrO}_{3}$-chromium chromitel is usually categorized as metal, and often used in an aqueous solution. Chromite, a compound of chromium, and crocoite, a lead chromate mineral, are the 2 principal forms of naturally occurring chromium. The former mineral is used commercially for the production of chromium containing materials. It is a highly stronger oxidizer agent, can easily evaporate, and is used in electroplating, metal cleaning, leather tanning, and photography.

This is a report of an individual with dental erosion as a consequence of working in a special industrial environment causing extreme toothwear.

\section{CASE REPORT}

A 52-year-old male patient referred to the Dental School of Kırıkkale University with a request for the elimination of the pain resulting from the upper right canine, and also treatment of his defective teeth. From his history, it was understood that he was a chemical engineer, and had been working in a chromium-plate-workshop for 20 years. The patient was a heavy smoker for 30 years $(25$ to 30 cigarettes/day). He did not drink fruit juices nor consume a high quantity of fruit or confectionery. His health was otherwise good and there were no symptoms to suggest salivary gland hypofunction.

He did not received any dental care for many years and neglected his oral hygiene. The oral mucosa appeared moist and healthy with clear saliva flowing freely from all major duct orifices. He had low previous caries experience and no active lesions were present.

$A$ vast destruction of the upper jaw teeth was obvious at first sight, particularly buccally. In the detailed examination, abrasion of the anterior teeth and premolars on both sides up to the marginal gingiva was visible in the upper and lower jaws (Figure 1). As a part of the dental examination, saliva from the patient was collected by ex- pectoration over a 10-minute period in the basal state and after stimulation by chewing on paraffin. Samples were immediately analyzed for buffering capacity using the Dentobuff Strip (Orion Diagnostica, Finland), and were found to be "medium level".

In the first stage, panoramic X-ray examination revealed a profound caries with pulpal involvement in tooth 13. This tooth was treated endodon-

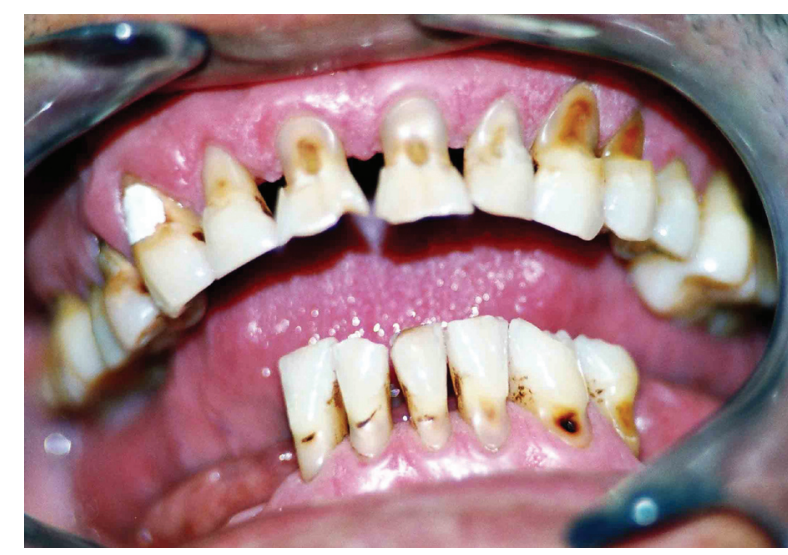

Figure 1. Overall clinical appearance of the erosive-abrasive defect in the upper and lower jaw involving all teeth.

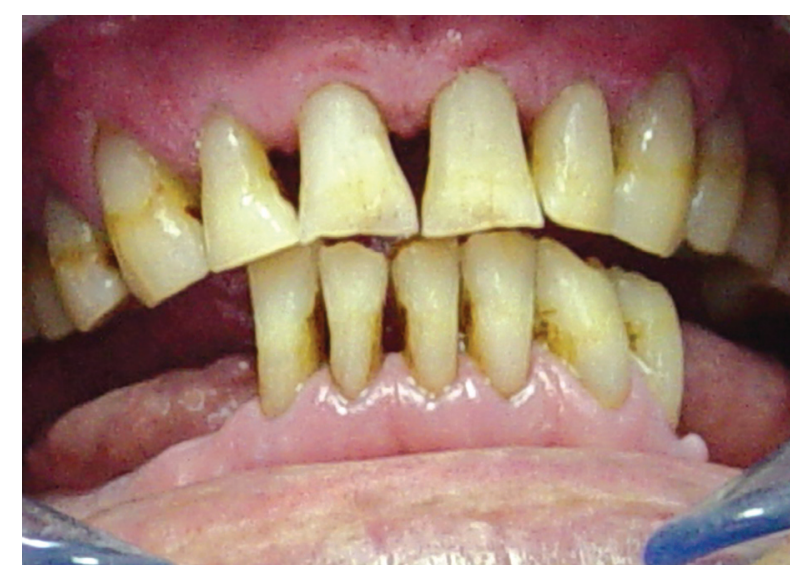

Figure 2. Frontal view of the cervically-restored-teeth with compomer restorative-material.

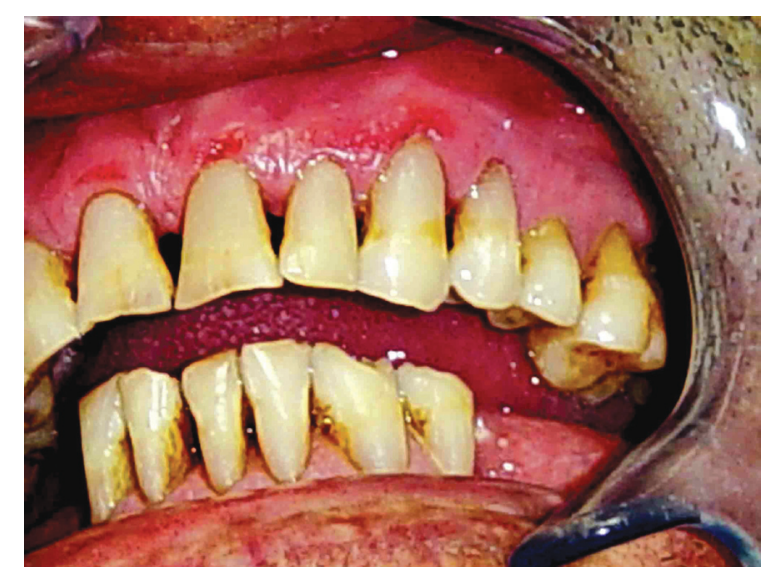

Figure 3. View of the restored upper and lower teeth from leftside. 
tically, using a root canal sealer (Sealapex, Kerr, USA) and the access cavity was sealed with temporary filling material. (3M-ESPE, Germany) In the second stage, dental calculus was removed and the patient was instructed and trained to be able to maintain proper oral hygiene.

Then the patient was advocated to use a $0.05 \%$ sodium fluoride rinse at least daily. Also, he advised not to brush excessively and to use a soft nylon toothbrush. Depending on the degree of tooth wear, restorative treatment was performed, using a compomer restorative material. The quadrant to be restored was isolated with cotton rolls, and dried with air-spray. After color selection, a single bond (Prime \& Bond NT, Dentsply, DeTrey, Germanyl was applied without cavity preparation. A compomer material (Dyract Extra, Dentsply, DeTrey, Germanyl was used incrementally and lightcured. The restorations were polished in the same appointment, using Soflex Disks (3m/ESPE, USA) (Figures 2 and 3 ).

\section{DISCUSSION}

In this case report, severe and extensive industrial erosion from chromic acid was treated by a compomer restorative material. As a general view of point, chromic acid has biohazardous effect by not only direct exposure but also occupational exposure via airborne fumes and/or elements. Certain effects such as contact dermatitis,, 10 skin ulcer, ${ }^{10}$ irritation and ulceration of the nasal mucosa, ${ }^{11}$ perforation of the nasal septum, ${ }^{12}$ and occasionally erosion and discoloration of the teeth $^{11,13}$ have been reported. Further, studies relating exposure to chromium compounds and incidence of dental caries indicated a low degree of correlation, but there was an increased incidence of gingivitis and periodontitis. Gomes ${ }^{11}$ reported the experience of electroplaters in the State of Sao Paulo, Brazil. Of the 223 workers, approximately $50 \%$ had yellowing and erosion of the teeth. Duration of exposure was unstated, but it was mentioned that the harmful effects were noted in less than a year, and that few workers remained many years in the industry. In our case, he announced 20 years working period in the chromium exposed occupation. When compared to aforementioned examples, clearly, this duration is high enough to result dental erosion.

Actually, erosion causes significant tooth wear and thereby dentine exposure at all sites on the anatomical crowns of the teeth and, particularly, in the cervical areas, where the enamel is very thin. Moreover, if toothbrush and acid from an occupational environment are combined, such as seen in our case, tooth wear escalates dramatically. An in vitro model simulating the chewing of abrasive acidic foods confirmed the potential for rapid enamel loss. ${ }^{14}$

In this case report, to restore cervical lesions a hybrid (compomer) material was selected due to its favorable clinical characteristics which are (i) color stability, (ii) biocompatibility, (iii) less plaque accumulation, (iv) flour releasing and esc. ${ }^{15}$ From various studies, it has been clearly understood that when compared the composite and/or amalgam restorations adjacent to the gingiva, hybrid materials show less adverse effect on gingival margin, clinical attachment level, pocket depth, width and thickness of the keratinized gingival; ${ }^{16}$ possess significantly lower plaque-gingival index, bleeding scores $;^{17}$ and produce fewer crevicular fluid. ${ }^{18}$ Also, in an in vivo study, Dragoo ${ }^{19}$ aimed the clinical and histological responses of the subgingivally placed hybrid-ionomer restorations in 50 cases, and concluded that these restorations could successfully be used to restore subgingival defects in where periodontal health is crucial, yielding an ideal epithelial and connective tissue adherence to these materials. Shortly, in view of all these studies, it can be concluded that if the restoration have to be placed subgingivally due to the localization of the tooth-defect, the suggested material should be hybrid-ionomer, having good biologic effect on marginal gingiva and periodontal tissue..$^{20}$

\section{REFERENCES}

1. Bruggen Cate HJ. Dental erosion in industry. Br J Ind Med 1968;25:249-266.

2. Asher C, Read MJ. Early enamel erosion in children associated with the excessive consumption of citric acid. Br Dent $J$ 1987; 162:384-387.

3. Petersen PE, Gormsen C. Oral conditions among German battery factory workers. Community Dent Oral Epidemiol 1991;19:104-106.

4. Lynch JB, Bell J. Dental erosion in workers exposed to inorganic acid fumes. Br J Ind Med 1947;4:84-86.

5. Malcolm D, Paul E. Erosion of the teeth due to sulfuric acid in the battery industry. Br J Ind Med 1961;18:63-69.

6. Litonjua LA, Andreana S, Bush PJ, Cohen RE. Tooth 
wear: attrition, erosion, and abrasion. Quintessence Int 2003;34:435-446.

7. Chikte UM, Josie-Perez AM, Cohen TL. A rapid epidemiological assessment of dental erosion to assist in settling an industrial dispute. J Dent Assoc S Afr 1998;53:7-12.

8. Chikte UM, Josie-Perez AM. Industrial dental erosion: a cross-sectional, comparative study. SADJ 1999;54:531536.

9. Fregert $\mathrm{S}$, Ovrum P. Chromate in welding fumes with special reference to contact dermatitis. Acta Dermatol Venereol 1963;43:119-124.

10. Walsh EN. Chromate hazards in industry. JAMA 1953;153:1305-1308.

11. Gomes ER. Incidence of chromium-induced lesions among electroplating workers in Brazil Ind Med 1972;41:21-25.

12. Cohen SR, Kramkowski RS. Health Hazard Evaluation Determination, Report No: 72. US Dept Health, Education, and Welfare, National Institute for Occupational Safety and Health, Division of Technical Services, Hazard Evaluation Services Branch. Cincinnati, Ohio, 1973:104-118.

13. Health of Workers in Chromate Producing Industry--A Study, Public Health Service publication 192. Federal Security Agency, Public Health Service, Division of Occupational Health of the Bureau of State Services, 1953.

14. Eisenburger M, Shellis RP, Addy M. Comparative study of wear of enamel induced by alternating and simultaneous combinations of abrasion and erosion in vitro. Caries Res 2003;37:450-455.

15. Ermis RB. Two-year clinical evaluation of four polyacid-modified resin composites and a resin-modified glass-ionomer cement in Class V lesions. Quintessence Int 2002;33:542-548.

16. Folwaczny M, Mehl A, Kunzelmann KH, Hickel R. Clinical performance of a resin-modified glass-ionomer and a compomer in restoring non-carious cervical lesions. 5year results. Am J Dent 2001;14:153-156.

17. Dragoo MR. Resin-ionomer and hybrid-ionomer cements: Part I. Comparison of three materials for the treatment of subgingival root lesions. Int $J$ Periodontics Restorative Dent 1996;16:594-601.

18. van Dijken JW, Sjostrom S. The effect of glass ionomer cement and composite resin fillings on marginal gingiva. $J$ Clin Periodontol 1991;18:200-203.

19. Dragoo MR. Resin-ionomer and hybrid-ionomer cements: part II, human clinical and histologic wound healing responses in specific periodontal lesions. Int $J$ Periodontics Restorative Dent 1997;17:75-87.

20. Anderegg CR. The treatment of class III maxillary furcations using a resin-ionomer. A case report. $J$ Periodontol 1998;69:948-950. 